\title{
Correlation Analysis between Crack and TQI in RC Slab Track
}

\author{
Se-Kon Kwon ${ }^{\dagger}$, Mi-Yun Park*, Doo-Kie Kim**, Byung-Choon Sho*, Jae-Hak Park*
}

\begin{abstract}
Recently, in the total railroad construction field, concrete slab tracks have been adapted in place of ballast tracks. Because ballast tracks need frequent maintenance and are difficult to handle due to increasing maintenance costs, eventually concrete slab tracks were selected as an alternative. However, owing to the hydration heat reactions and temperature-affected shrinkage of the concrete, a variety of studies to solve maintenance problems related to concrete slab tracks are underway. This study analyzed characteristics of TQI values evaluating track irregularity, investigated the relationship between crack progress and TQI, and then evaluated the correlation between the two values. Through our analysis, we found that there is a need to supplement the problems of the current method and develop a track evaluation index which takes cracking into account. We also concluded that TQI is the main decision-making tool in track maintenance.
\end{abstract}

Keywords: Concrete slab track, Track irregularity, Crack, TQI values, Correlation, Decision making in track maintenance

\section{Introduction}

Ballast tracks, which once dominated most of track in the Korean railway, are now being gradually replaced by concrete slab tracks. In contrast to the ballast tracks, concrete slab tracks are perceived to be structurally more stable and have dramatically cheaper maintenance costs. Thus, concrete slab tracks are being evaluated as having a competitive edge over ballast tracks when it comes to the overall life cycle of the track structure. However, the concrete slab tracks have several problems. The biggest issues have to do with the cracks that occur between sleepers and the concrete slabs, leading to sleeper moving, displacements and track irregularity. The cracks between the sleepers and concrete slabs may be caused by temperature and drying shrinkage. However, especially noteworthy here is that most cracks are intimately related to the construction quality during the laying down of the tracks. Consequently, the technical supervision of crack control and management is

\footnotetext{
$\uparrow$ Corresponding author: Korea Railroad Corp., Korea E-mail : tibobkr@korail.com

* S. H. Tech \& Policy Institute., Korea

** Department of Civil Engineering, Kunsan National University, Korea

(C) The Korean Society for Railway 2014

http://dx.doi.org/10.7782/IJR.2014.7.1.008
}

very important. The cracks that occur at the sleeper edges during train operation can widen very rapidly depending on impact by vehicle impact load, volume of traffic, changes in climate, and vehicle operation speed. Also a crack at one sleeper will lead to cracks in adjacent sleepers, which can cause significant problems not only for bad ride quality but also for train derailment. Therefore, it is essential that maintenance strategies for crack control are set in place from the operation starting stage.

The Track Quality Index (TQI) method is a tool for measuring track quality. Track irregularity is predicted for each given section; then, according to track attributes or characteristics, each section is given a TQI. The following are methods to evaluate the characteristic of track quality as determined by TQI: Peak Value, P -Value, and standard deviation. The Peak Value method directly utilizes the inspected track irregularity data as maintenance specifications. The P-Value method manages the track irregularity by each section; track irregularity is shown by considering the proportion of tracks that are irregular by over $3 \mathrm{~mm}$. The track quality assessment method of the U.S. Federal Railroad Administration (FRA) utilizes the actual measured length of the tracks. Track length is measured against the theoretical length of a given track segment. Based on the differences, surface curves and degrees of impediment 
are assessed. Then, TQI is calculated. In such a method, data is analyzed by using inspected track data. However, in case of track irregularity that relies on TQI, the radical problem of track irregularity is not found. Rather, only the differences between past records and current measures are being compared. The researchers of this study think that such a method is not a track maintenance method based on fundamental cause analysis. To search effective methodology about this problem, operating concrete slab tracks railway sections in tunnels were selected and were examined. Based on the detailed crack inspection data performed by the Korea Railroad Corporation (hereafter "Korail") from $2006 \sim 2010$ on the concrete slab tracks, the researchers executed an analysis based on the row data and expert opinions, concerning the occurrence and progression of cracks. The correlation between track irregularity and characteristics in crack size change should be analyzed. After all in the future, the decision-making for railway maintenance of concrete slab tracks is not made separately from the decision-making for crack maintenance, and it is important the decision-making for railway maintenance should be evaluated together. Instead, the change in measured values of inspected track irregularity should be considered at every quarter, and inspection and repair for cracks should be performed on a regular basis. If such regular inspection and repair of cracks occurs, future economic loss and aging of railway structures will be prevented. Thus, the purpose of this study would be fulfilled.

\section{Analysis of Relation between Track Crack and TQI}

Generally, the fundamental cause behind cracks and early degradation in concrete structures stems from either poor quality or negligence during construction. Concrete cracks are unavoidable due to the following reasons: 1) the original properties of the material used for constructing with concrete, 2) excessive loading, 3) inconsistent conditions during construction, and 4) internal factors within the concrete. However, cracks that occur in concrete slab tracks are different from those that occur in other concrete structures. The repeated impact loading from trains causes cracks to gradually widen which may potentially lead to roadbed damage and sleeper fallouts. Therefore, it is critical to manage and repair any crack occurrences at their initial stages.

To analyze the major factors for the occurrence and progression of tracks, the researchers conducted a survey on 43 individuals who are currently working at Korail with experience in maintenance of concrete slab tracks. Looking at the survey results comprehensively, the workers recognized that there was a high correlation between track
Table 1. Survey Results from Experts (Korail - Jeonbuk HQ)

\begin{tabular}{|c|c|c|}
\hline Content & Survey results & Ratio \\
\hline $\begin{array}{l}\text { Correlation } \\
\text { between crack } \\
\text { and track } \\
\text { irregularity }\end{array}$ & High & $91 \%$ \\
\hline $\begin{array}{c}\text { Cause of track } \\
\text { irregularity }\end{array}$ & Sleeper displacement & $56 \%$ \\
\hline & Poor design & $72 \%$ \\
\hline $\begin{array}{l}\text { Main factor } \\
\text { for cracks }\end{array}$ & $\begin{array}{l}\rightarrow \text { Increase in passing tonnage } \\
\quad \rightarrow \text { Poor construction } \\
\text { Poor construction } \rightarrow \text { Increase in } \\
\text { passing tonnage } \rightarrow \text { Poor design }\end{array}$ & $70 \%$ \\
\hline $\begin{array}{l}\text { Time for crack } \\
\text { repairs }\end{array}$ & When it is smaller than $0.5 \mathrm{~mm}$ & $84 \%$ \\
\hline $\begin{array}{l}\text { Best time of } \\
\text { repair for crack } \\
\text { control }\end{array}$ & Within 3 months & $\begin{array}{c}\text { For cracks that } \\
\text { progress from } \\
0.3 \mathrm{~mm} \rightarrow \\
0.5 \mathrm{~mm}\end{array}$ \\
\hline
\end{tabular}

irregularity and the pace at which cracks progress and expand after they occur.

\subsection{Current situation and characteristics of crack occurrence in concrete slab tracks}

The following are the major factors that cause crack occurrence in concrete structures: drying shrinkage and temperature change, structural factors, unequal loading, and land subsidence. These same factors apply for the cracks that occur in railway tracks. But in case of tracks, there are the additional factors of passing loads and impact loading from trains that run over the tracks. Thus, crack occurrences are frequent in sleepers as well as concrete slab tracks. The cracks in sleepers and concrete slabs not only can lead to delays in train operations but in the worstcase scenario, the cracks may lead to train derailment. Crack occurrence is therefore a very serious issue.

2.1.1 Current situation of crack occurrence in concrete slab tracks

To analyze the current situation of crack occurrence in concrete slab tracks, the researchers examined the data from detailed track inspections conducted by Korail from 2006 to 2009 on an annual basis. The inspections were performed on sleeper-embedded concrete slab tracks which were constructed on the Jeolla Line.

\section{A. Current situation of crack occurrence}

Based on the analysis of the detailed inspection data on concrete slab tracks, the following was observed for the current situation of crack occurrence: numerous cracks 


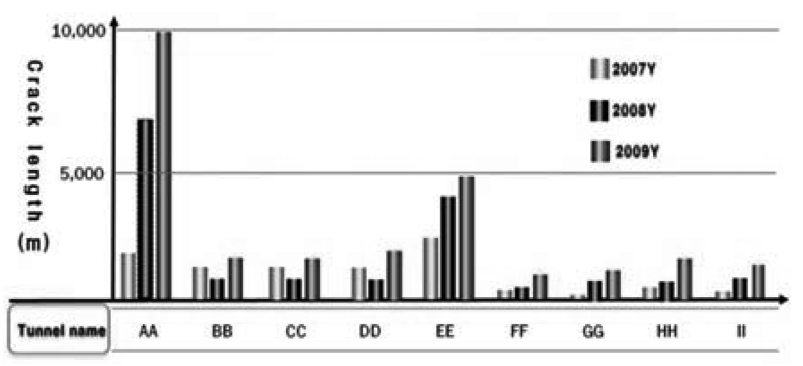

Fig. 1 Graph showing increasing trend of crack occurrences by year (Korail Jeon-buk HQ, 20082009 Detailed Inspection Data)

were distributed both in longitudinal and lateral directions and distributed throughout the slabs and sleeper edges. As can be seen in Fig. 1, the crack lengths in every concrete slab track inspected are continuously increasing from year to year. Such increase in cracks can be linked to failure in crack repairs upon initial crack occurrence and the spreading of cracks due to repeated impact loading from trains.

\section{B. Types of crack occurrences}

After analyzing the detailed inspection data on concrete slab tracks and conducting on-field inspections, the following were the representative types of cracks that were observed in concrete slabs.

\section{(1) Longitudinal cracks}

The longitudinal cracks that occurred in concrete slab tracks were distributed throughout the slab shoulders at the inside and outside of the track gauge and also at the installation of the longitudinal rebars (reinforcing bars). They can be categorized into three types.

- Type A: crack along the end of slab (TCL layer)

- Type B: crack progressing at point $10 \sim 20 \mathrm{~cm}$ away from end of slab (TCL layer)

- Type C: crack occurring along the horizontal rebars

\section{(2) Lateral cracks}

Lateral cracks on concrete slab tracks occurred in all sections of the slab (TCL layer) in various distributions. They can be categorized into the following three types.

- Type A1: crack from end of slab (TCL layer) to end of sleeper

- Type B1: lateral crack from one end or both ends of sleeper

- Type C1: lateral crack between sleepers

(3) Concrete sleeper edge cracks which cause slab and sleeper to be separated

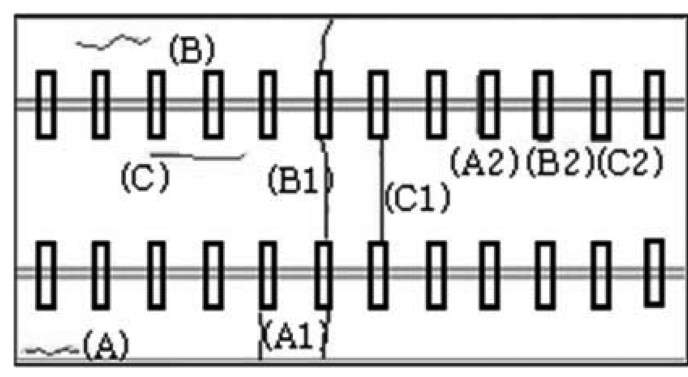

Fig. 2. Types of cracks on concrete slab tracks

Table 2 Crack Occurrences by Spans (Korail Jeonbuk HQ, 20082009 Detailed Inspection Data)

\begin{tabular}{cccccc}
\hline \hline Year & 2008 & 2009 & & & \\
\hline \multirow{2}{*}{$\begin{array}{c}\text { Span } \\
\text { No. }\end{array}$} & $\begin{array}{c}\text { Crack } \\
(\mathrm{mm})\end{array}$ & Sites & $\begin{array}{c}\text { Lengths } \\
(\mathrm{m})\end{array}$ & Sites & $\begin{array}{c}\text { Length } \\
(\mathrm{m})\end{array}$ \\
\hline \multirow{5}{*}{ S1 } & 0.3 & 18 & 30.6 & 1 & 1.7 \\
\cline { 2 - 6 } & 0.5 & 8 & 13.6 & 31 & 52.7 \\
\cline { 2 - 6 } & 0.7 & 2 & 3.4 & 22 & 34.7 \\
\cline { 2 - 6 } & 1.0 & 1 & 1.7 & 14 & 23.8 \\
\cline { 2 - 6 } & 1.5 & 0 & 0.0 & 0 & 0.0 \\
\cline { 2 - 6 } & 2.0 & 0 & 0.0 & 0 & 0.0 \\
\hline \multirow{4}{*}{ S20 } & Total & 29 & 49.3 & 68 & 112.9 \\
\cline { 2 - 6 } & 0.3 & 36 & 59.8 & 28 & 46.2 \\
\cline { 2 - 6 } & 0.5 & 22 & 37.4 & 29 & 49.3 \\
\cline { 2 - 6 } & 0.7 & 0 & 0.0 & 8 & 13.6 \\
\cline { 2 - 6 } & 1.0 & 1 & 1.7 & 1 & 1.7 \\
\cline { 2 - 6 } & 2.0 & 0 & 0.0 & 0 & 0.0 \\
\hline & Total & 59 & 98.9 & 66 & 110.8 \\
\hline
\end{tabular}

Results from regular inspections showed that cracks along concrete sleepers which cause slab and sleeper to be separated were occurring frequently in all areas. There are the following three types of such cracks.

- Type A2: Sleeper edge crack occurring in one direction at slab and concrete sleeper embedding

- Type B2: Sleeper edge crack occurring in both directions at slab and concrete sleeper embedding

- Type C2: Sleeper displacement followed by sleeper edge crack occurring in four directions at slab and concrete sleeper embedding

2.1.2 Analysis of progression/expansion of cracks in concrete slabs

To conduct an examination of the progression/expansion speed of cracks, the researchers analyzed data on the 


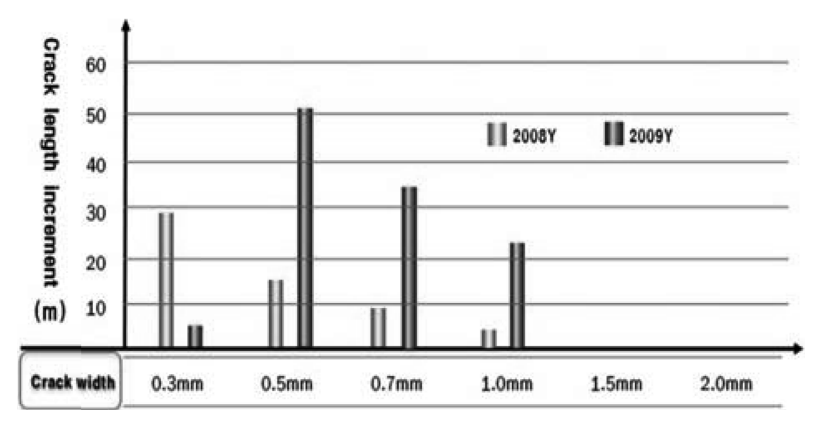

Fig. 3 Progression speed of crack width and increase of quantity according to passing of time (Korail Jeonbuk HQ, 20082009 Detailed inspection data)

A Tunnel, done by span units. The crack sizes were taken from $0.3 \mathrm{~mm}$ to $2.0 \mathrm{~mm}$ at spans $\mathrm{S} 1 \sim \mathrm{S} 20$. Analysis was conducted on annual increase.

Looking at the data on the twenty spans, it can be seen that most cracks have progressed in length and that the progression is considerably large in value.

Between 2008 and 2009, it can be observed that cracks which expanded from $0.3 \mathrm{~mm}$ to $0.5 \mathrm{~mm}$ increased in quantity by approximately $20 \mathrm{~m}$. Cracks which expanded from $0.5 \mathrm{~mm}$ to $0.7 \mathrm{~mm}$ also increased by about $20 \mathrm{~m}$. The same was observed for cracks that expanded from $0.7 \mathrm{~mm}$ to $1.0 \mathrm{~mm}$; there was an increase of approximately $20 \mathrm{~m}$. Across the board, there are almost identical patterns of increase. Fig. 3 shows the progression of cracks during a two-year time period.

\subsection{Analysis of the relation between TQI based on track inspection measurement data and cracks}

Management of track irregularity requires the biggest proportion of time and resources in track maintenance. To predict the progression of such track irregularities, tracks must be segmented so that homogeneity can be guaranteed according to track properties such as type of track components, the presence of structures, and type of roadbeds. Segmentation allows long-term observation of track qualities. Each section of a track that has homogeneity is defined as a segment. Then track quality is measured and managed at each segment; thus, progression of irregularities is predicted. In this study, the track length-based quality assessment method as proposed by the U.S. FRA was adapted to calculate the TQI for each track inspection parameter that was measured during track inspection. The track irregularities occurring on concrete slab tracks were analyzed by utilizing track inspection data from 2005 to
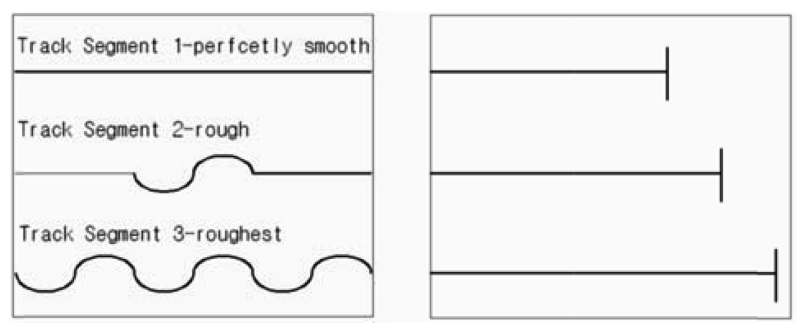

Fig. 4 TQI approach based on track length

2010. The tracks under inspection were the spans along the AA tunnel on the Jeolla Line. The spans were selected for this study because crack occurrences were increasing every year along the spans. TQI analysis was conducted for the selected spans. For TQI calculations, data from track inspections at every $1^{\text {st }}$ quarter (EM-120) in the years 2007 to 2010 were utilized. To analyze progression of track irregularities by year, four categories - Case 1, 2, 3, and 4 - were created according to year of operation. Each span was given a segment length of $40 \mathrm{~m}$.

The following is a description of TQI theories, formulas and figure. At frist, it is measured the distance between the two end in a track segment, in which have a rough, winding surface, and the more track irregularity is the longer actual length becomes in the segment.

Using that method, track condition status is expressed as the relative values,not absolute values. Using the following simple triangle formula, the measured total length in each measuring part is calculated in FRA.

$$
L_{s}=\sum_{i=1}^{n} \sqrt{\left(y_{i+1}-y_{i}\right)^{2}+\left(x_{i+1}-x_{i}\right)^{2}}
$$

Here, $L_{s}:$ the measured total length

$y_{i+1}-y_{i}$ : the distance gap between theoretical value and actual value, $x_{i+1}-x_{i}$ : the distance of two points.

The total length of each segment is obtained by measured, the track torsion data through the analysis of distance gap against the theoretical length can be obtained. This information is utilized to evaluate the quality of the track per track segment .Here is the track quality index (TQI)Equation defined in FRA.

$$
T Q I=\left(\frac{L_{S}}{L_{0}}-1\right) \times 10^{6}
$$

Here, $L_{0}$ : the theoretical length of the segment

2.2.1 Relationship between longitudinal irregularity TQI and cracks

To confirm the dynamic relationship between TQI and 


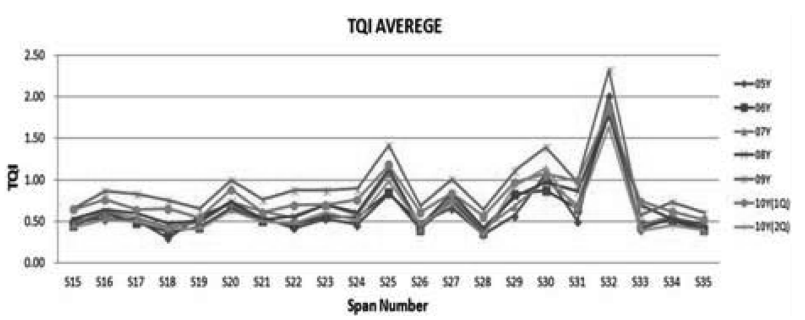

Fig. 5 Changes in longitudinal irregularity TQI values along AA tunnel northbound-lane (S15-S35) (Korail Jeonbuk HQ, 20052010 Track Inspection Data)

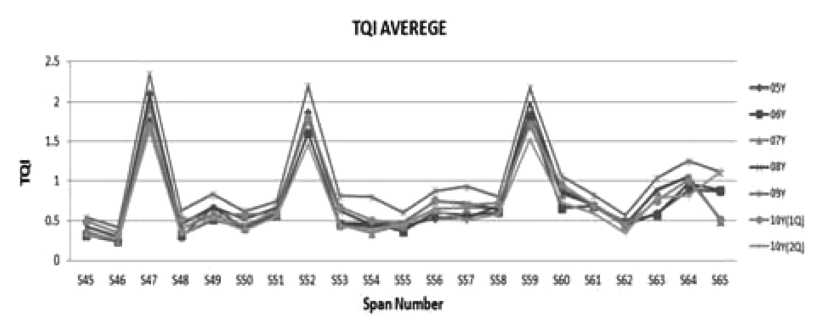

Fig. 6 Changes in longitudinal irregularity TQI values along AA tunnel northbound-lane (S45-S65) (Korail Jeonbuk HQ, 20052010 Track Inspection Data)

cracks, the researchers inspected and recorded the TQI values and extents of cracks at 180 segments in both north and south-bound lanes over a five year period. Figs. 3 and 4 show some of the longitudinal irregularity TQI along the inspected sections. For these sections, crack repairs were conducted twice, first at the end of 2009 and the second at the beginning of 2010. Thus, they are sections for which changes in TQI values due to repair can be confirmed. Looking at several circumstances in these sections prior to the repairs, it can be seen that actual inspections showed longitudinal irregularity TQI and crack depth to be deep. In areas with bigger displacements, the TQI was greater. Actual inspection results also showed that the number of both crack occurrences and sleeper displacements increased every year. At the same time, TQI was increasing every year as well.

2.2.2 Relationship between irregularity in line TQI and cracks

Trends in irregularity in line TQI showed no consistent pattern and a rather scattered distribution. However, after crack repairs were conducted, irregularity in line TQI increased. This seems to be caused by the current method of crack repair. The chock installed after epoxy injection causes impact which leads to directional irregularity. It is the judgment of the researchers that, because of the directional irregularity, the irregularity in line TQI was momen-

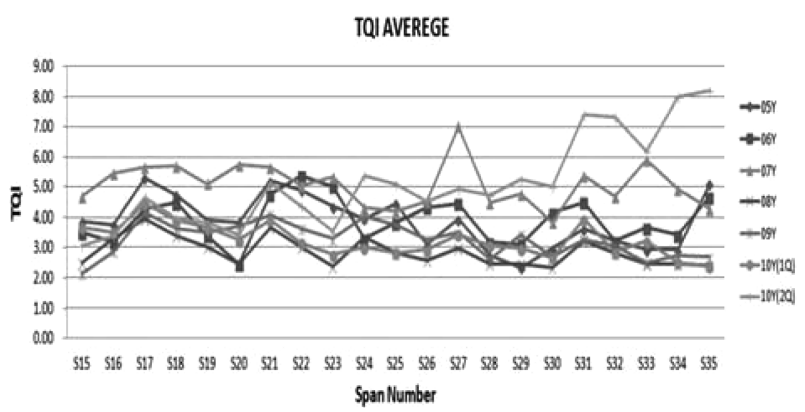

Fig. 7 Changes in irregularity in line TQI values along AA tunnel northbound-lane (S15-S35) (Korail Jeonbuk HQ, 20052010 Track Inspection Data)

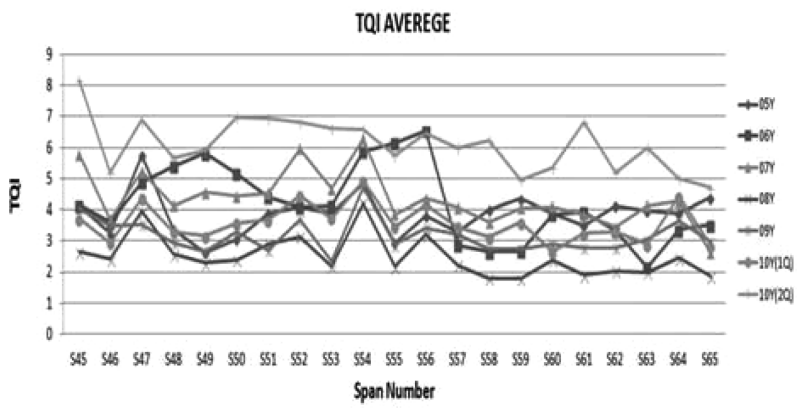

Fig. 8 Changes in irregularity in line TQI values along AA tunnel northbound-lane (S45-S65) (Korail Jeonbuk HQ, 20052010 Track Inspection Data)
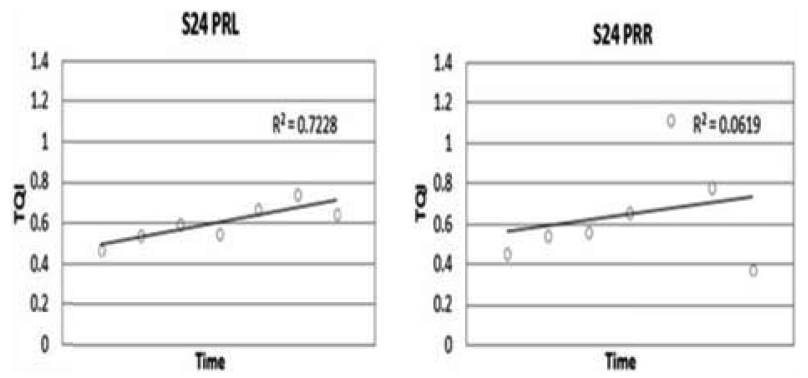

Fig. 9 Changes in TQI Values following crack repairs in AA Tunnel (S24) (Korail Jeonbuk HQ, 20052010 Track Inspection Data)
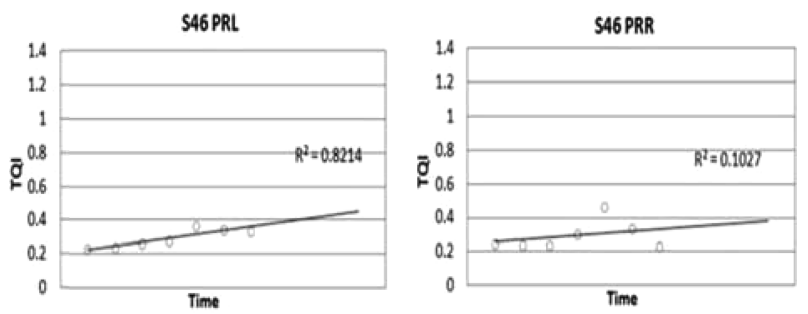

Fig. 10 Changes in TQI Values following crack repairs in AA Tunnel (S46) (Korail Jeonbuk HQ, 20052010 Track Inspection Data) 
tarily influenced and increased. To prove this conjecture, the researchers conducted a time series analysis. As can be seen in Figs. 7 and 8, both irregularity in line TQI and longitudinal irregularity TQI show much smaller values than before crack repair.

\subsection{Correlation analysis between actual measurement graph of track inspection and cracks}

Of the track inspection graphs for tracks that have been in operation for four years after initial opening, the graphs for the AA tunnel was selected for the noticeably large increase in crack occurrences year by year. At two sections along the AA tunnel (S17, S49), four samples were randomly selected and longitudinal irregularity and progression were analyzed.

\section{A. Track inspection graph samples}

1) Section 1 (S15 S35): Sample 1 ('06.03), Sample 2 ('07.03), Sample 3 ('08.03), Sample 4 ('09.03)

2) Section 2 (S45 S65): Sample 1 ('06.03), Sample 2 ('07.03), Sample 3 ('08.03), Sample 4 ('09.03)

\section{B. Analysis of track inspection graphs}

To analyze the track inspection graphs, four samples were first selected. Then with Sample 1 ('06.03), as the reference, Samples 2('07.03) to Samples 4('09.03)were superimposed /duplicated. The occurrence of longitudinal irregularity and progression following the passing of time were directly analyzed by visual observation.

Analysis of Section 1, shows that, with Samples 1 and 2, the track conditions (line) are almost identical and thus it can be assumed that track irregularity is absent. However, in the case of Sample 3 where crack occurrence rapidly increases, track condition (line) does not line up, which means that longitudinal irregularity has progressed. The track condition in Sample 4 is poorer than that of Sample 3. Thus, it can be seen that longitudinal irregularity has rapidly progressed during one year. To analyze the relationship between cracks and changes in track inspection graphs of Samples 3 and 4, the researchers compared the crack development drawings for 2009 with the drawings for 2008. The comparison shows that crack size has rapidly increased from $0.7 \mathrm{~mm}$ to $1.5 \mathrm{~mm}$ and that sleeper displacement has occurred. Additionally, for sites where the TCL layer does not line up with RC sleepers (i.e. sites where there has been sleeper displacement: 35 36, 44 45), the train load during its passing becomes concentrated on adjacent sleepers $(37 \sim 38,42 \sim 43,46 \sim 48)$. Consequently, cracks in the adjacent sleepers were rapidly spreading.

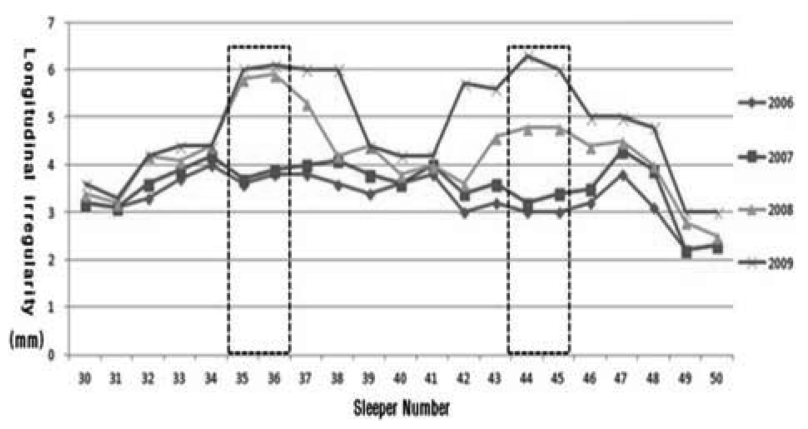

Fig. 11 Track inspection (longitudinal irregularity) graph (S17) (Korail Jeonbuk HQ, 20062010 Track Inspection Data)

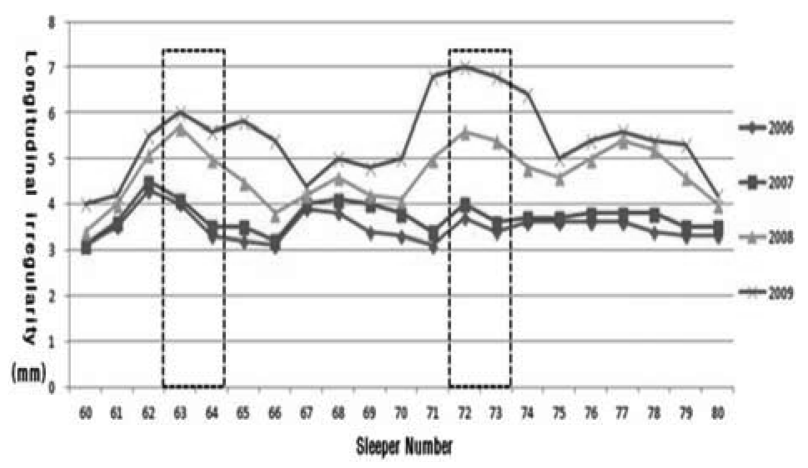

Fig. 12 Track inspection (longitudinal irregularity) graph (S49) (Korail Jeonbuk HQ, 20052010 Track Inspection Data)

Analysis of Section 2 showed that, just like Section 1, the track condition of Sample 4 was poorer than that of Sample 3. It could be seen that cracks were rapidly increasing and causing sleeper displacements.

In conclusion, the analysis results for Sections 1 and 2 show that cracks are intimately correlated with track irregularity.

\subsection{Correlation Analysis between Cracks and TQI}

2.4.1 Correlation analysis between cracks and TQI

The analysis results above clearly demonstrate that there are changes in TQI values due to cracks. But much research is still necessary in order to find out if indeed cracks are the fundamental cause of track irregularity. There may be other root causes including structural problems such as lower roadbed settlement or faulty construction. Or, the cracks that this study has noted may be the main cause behind changes in TQI. Therefore, to analyze the numerical correlation between cracks and TQI, the researchers used Minitab, a statistical analysis program, and conducted a correlation analysis between TQI and cracks inspected for the years 2008 to 2009 . The analysis 
Table 3 Correlation analysis between TQI and Cracks

\begin{tabular}{|c|c|c|c|c|c|c|}
\hline \multirow{2}{*}{$\begin{array}{c}\text { Category } \\
\text { Analyzed year }\end{array}$} & \multicolumn{2}{|c|}{$\begin{array}{c}\text { S(northbound) } \\
15-\mathrm{S} 35\end{array}$} & \multicolumn{2}{|c|}{$\begin{array}{c}\text { S(northbound) } \\
45-S 65\end{array}$} & \multicolumn{2}{|c|}{$\begin{array}{c}\text { S(northbound) } \\
84-S 104\end{array}$} \\
\hline & '08 & '09 & '08 & '09 & '08 & '09 \\
\hline $\begin{array}{l}\text { Product-moment } \\
\text { correlation } \\
\text { coefficient }(\mathrm{T})\end{array}$ & 0.86 & 0.77 & 0.72 & 0.80 & 0.81 & 0.80 \\
\hline $\begin{array}{c}\text { Test statistic } \\
\text { (P-value) }\end{array}$ & 0.00 & 0.00 & 0.00 & 0.00 & 0.00 & 0.00 \\
\hline
\end{tabular}

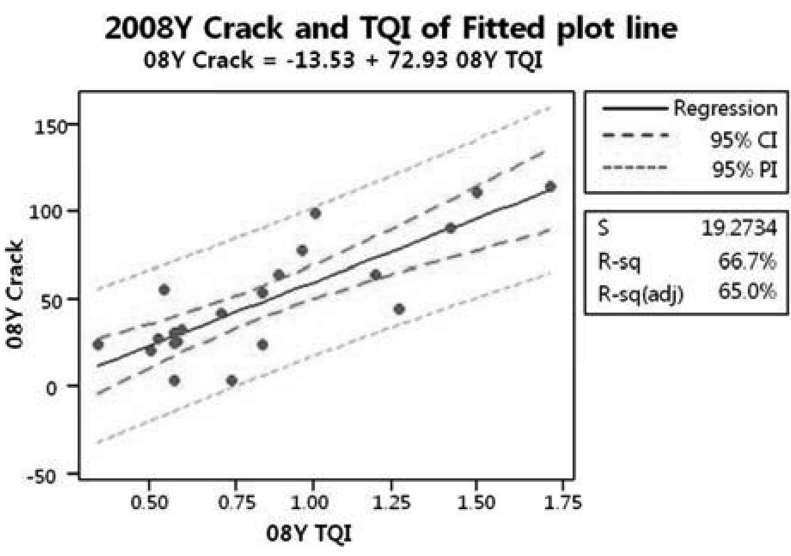

Fig. 13 Conformance verification for cracks and TQI in 2008

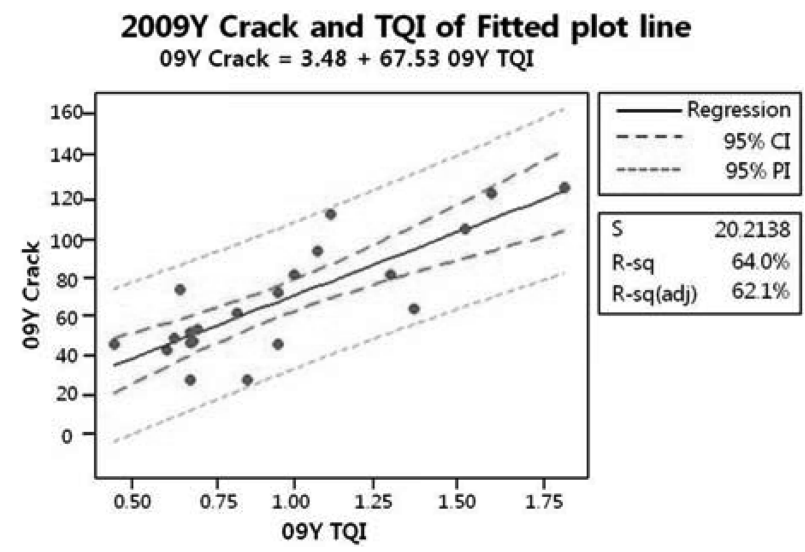

Fig. 14 'Conformance verification for cracks and TQI in 2009

was conducted at a $95 \%$ confidence level. The correlation coefficient obtained through the analysis is shown in $<$ Table $3>$. The range of the correlation coefficients lies between 0.7 and 0.9 . This is numerical proof that there is a relatively high level of correlation between the two data sets. Additionally, the test statistic (P-value) was shown to have a significance level less than $5 \%$. Thus, that there is a correlation between cracks and irregularities was statistically validated.

2.4.2 Regression analysis between crack and TQI
During regression analysis, a scatterplot analysis was made for cracks and TQI in the years 2008 and 2009. Thus, the correlation between the two variables could be predicted. A hypothesis on the relationship between cracks and TQI was set up. Then, statistical verification at a $5 \%$ level of significance was conducted. As can be seen from the drawing below, regression analysis showed that both the cracks and TQI values are included within the $95 \%$ confidence interval. Furthermore, since the test statistic (Pvalue) was analyzed to have a significance level of less than $5 \%$, it can be seen that the regression equation between cracks and irregularities is statistically significant. This finding will be critical in presenting a new direction for decision-making in the maintenance of concrete slab tracks.

\section{Conclusion}

The majority of track engineers believe that track irregularities are minimal in the tracks they design and construct. Additionally, until now, there have been no problems in track maintenance and ride quality due to crack occurrences in concrete slabs. However, the results from the correlation analysis between cracks and TQI clearly show that cracks have for a great influence on fundamental track irregularity. Of particular note, it was confirmed that the cracks around sleepers trigger sleeper displacements which lead to a very high correlation between cracks and longitudinal irregularity TQI. It could be also seen that cracks that occur on concrete slab tracks rapidly progress at a certain point and spread to adjacent sleepers depending on train operation circumstances (passing tonnage, train speed, number of train operations). Therefore, for the stable maintenance of concrete slab tracks in the future, decision-making for line maintenance should not be made separately from decision-making for crack maintenance. Rather, the longitudinal irregularity measured during track inspection should be carefully examined so that crack inspections can take place on a regular basis. The researchers of this study strongly emphasize the need to set up a maintenance plan for concrete slab tracks that will allow regular crack inspections. Such a maintenance plan would provide a standard for decision-making regarding the maintenance of concrete slab tracks, and maintenance should be conducted according to this standard.

\section{Reference}

1. Kwon, Se-kon, Mi-yun Park, Doo-kie Kim, and Jae-hak Park (2012), "Correlation Analysis between Crack and TQI in RC 
Slab Track", Journal of the Korean Society of Societal Security, Vol. 5 No. 2, pp. 71-79.

2. Kim, Nam-Hong, Syeung-Yeol Lee, Byoung-Koo Woo, Myung-Su Kim, and Sung-Uk Lee (2009), "Comparative Analysis on Track Quality Index (TQI) Methods", Fall Symposium Journal of the Korean Society for Railway, pp. 26672673.

3. Park, Kil-Bae and Kang-Wun Lee (2007), "The Study for the Modeling Method for Creating Track Data with the Irregularity for Use as the Input to a Rail Vehicle Dynamic Analy- sis", Fall Symposium Journal of the Korean Society for Railway, pp. 21-26.

4. Lee, Jeeha, Il-Yoon Choi, and Bag-Jin Kim (2008), "Comparison of Track Recording with Surveying in Track irregularity Measurement", Symposium Journal of the Korean Society for Railway, pp. 1090-1095.

5. Lee, Jeeha and You Bok Choi (2009), "Application of Track Recording Data for Track Maintenance", Fall Symposium Journal of the Korean Society for Railway, pp. 3057-3063 